\title{
Clinicopathological evaluation of sinunasal neoplasm in a tertiary care hospital
}

\author{
Koushik Dewan ${ }^{1}$, Ritam $\mathrm{Ray}^{2}$, Dipanwita Nag ${ }^{3}$, Mamata Guha mallick (Sinha) ${ }^{4}$, \\ Subrata Mukhopadhyay ${ }^{5}$, Sudarshana Raychaudhury ${ }^{6}$, Gautam Kumar Mandal ${ }^{7}$ \\ 1. Senior resident, Dept. Of Pathology, Chittyaranjan National Cancer Institute 37, S.P.Mukherjee Road, \\ Kolkata-700026, West Bengal, India \\ 2. RMO-cum-clinical tutor, Dept. Of ENT, Burdwan Medical College \& Hospital, P.O. - Rajbati, Burdwan- \\ 713104, West Bengal, India \\ 3. Associate professor, Dept. Of Pathology, Medical College Hospital, Kolkata 88, College Street, Kolkata \\ - 700073, West Bengal, India \\ 4. Professor, Dept. Of Pathology, North Bengal Medical College \& Hospital, Sushrutanagar,Darjeeling - \\ 734012, West Bengal, India \\ 5. Professor, Dept. Of Pathology, Medical College Hospital, Kolkata 88, College Street, Kolkata-700073, \\ West Bengal, India \\ 6. Dept. Of Pathology, Medical College Hospital, Kolkata 88, College Street, Kolkata-700073, West \\ Bengal, India \\ 7. Associate professor, Dept. Of Pathology, Chittyaranjan National Cancer Institute 37, S.P.Mukherjee \\ Road, Kolkata - 700026, West Bengal, India
}

Abstract: Objective: Though sinu-nasal neoplasms comprise of a small percentage of head neck tumours, they areincreasing in incidence due to rapid industrialization and an increase in life expectancy. Further in many cases they present at an advanced stage and data from studies on them from eastern region of the country is limited, encouraging this study. The aim of this study to evaluate the clinical and demographic profile as well as the histological variation of sinunasal neoplasms and it relation with occupation and addiction.

Methods:
Design:
Prospective study
Setting:
Tertiary government teaching hospital
Participants: All patients presenting with neoplastic lesion in nasal cavity between December, 2009 to May, 2011

Results: Eighty two(82) patients-- 57 (69.51\%) male and 25 (30.49\%) female aged upto 80 years, were included, displaying male predominance and clustering in the fifth decade of life. Benign lesions (44 cases, $53.66 \%)$ were more common than the malignant lesions (33 cases , $40.24 \%$ ) and 5 cases $(6.10 \%)$ were seen indeterminant for malignancy/low-grade malignant potential. Most common anatomical location was nasal cavity(57.32\%) and farmers were mostly affected by sinonasal neoplasm (30\%). Commonest clinical presentation was epistaxis $(31.71 \%)$.

Conclusion: Sinonasal neoplasms have wide range of possibilities. Commonly, patients present with nasal obstruction and epistaxis. Early diagnosis with the help of newer diagnostic modalities with prompt treatment is necessary for these patients. Histopathological diagnosis is necessary for any neoplastic lesion in nasal cavity. This will guide us for further management of these lesions

Keywords: Paranasal sinus ; Neoplastic lesion ; Nasal obstruction ; Epistaxis ; Sinonasal neoplasm

\section{Introduction}

Sinonasal disease is one of the most common clinical head and neck pathologies. The majority of sinonasal lesions are inflammatory with neoplasms comprising approximately $3 \%$ of all head and neck tumours ${ }^{1}$. Although the sinonasal tract and nasopharynx have identical appearing ciliated respiratory epithelium, the epithelium of the sinonasal tract is ectodermally derived, while that of the nasopharynx is endodermally derived. These structures may give rise to identical neoplasms that differ only in their location and resulting clinical symptomatology $y^{2}$.Though the nasal cavity and paranasal sinuses occupy a relatively small anatomical space, they are the site of origin of some of the more complex, histologically diverse group of tumors in the entire human body. Moreover they vary widely depending on the age, occupation and addiction habits and other environmental factor related to the patient.Thus they provide a challenging as well as interesting area for detail study for both the histolopathologist as well as the otorhinolaryngologist. So we were more interested in documenting such neoplasms from a teriary care hospital in eastern india. 


\section{Materials And Methods}

The present study was carried out at the Department of Pathology and the Department of ENT, Medical College \& Hospital, Kolkata during the period December, 2009 to May, 2011. It comprises of 82 patients with sinunasal mass who attended the E.N.T outpatient Department of Medical College \& Hospital, Kolkata from December, 2009 to May, 2011.

All the patients were evaluated carefully with thorough history taking and a complete ENT examination after admission. CT scan was routeinly done in all cases for better correlation. Peroperative details was collected. Histopathological examination of all surgically removed specimens was done and correlated with clinical diagnosis. The statistical tests were done using the software $\mathrm{Med} \mathrm{Cal}^{3}$

\section{Results}

In the study population, males $(69.51 \%)$ were more commonly affected than females $(30.49 \%)$. Maximum patients with sinonasal mass were found in the age group of 41-50years (Table - 1). Males in their $5^{\text {th }}$ decade of life and females in their $1^{\text {st }}$ decade of life were more commonly affected. No case was found among female above 70 years of age. It was also observed that there was increased incidence among males ( $>40$ years) than female.

It was observed that most common benign lesions among male and female both sexes were found in the age group 10-20 yrs, whereas malignant lesions mostly found in the age group 41-50 years. No sigficant age association was found with indeterminant group.

In our study, it was observed that benign lesions were more common than the malignant lesions accounting for 44 cases $(53.66 \%)$ and 33 cases $(40.24 \%$ ) of all cases respectively and 5 cases $(6.10 \%)$ were seen indeterminant for malignancy/low-grade malignant potential (Fig.I).

It was found that farmers were mostly affected by sinonasal neoplasm (30\%), followed by labours (22\%), house wives (20\%) respectively. Less no of cases were found among unemployed, businessman and office worker. After proper history taking it was found that 16 cases among 82 total cases (19.51\%) had significant addiction or occupational history (Fig. II).

Most common anatomical location was nasal cavity $57.32 \%$, followed by nasopharynx $13.41 \%$, maxillary antrum $13.41 \%$ (Fig.IV), nasal septum $8.54 \%$, other locations $7.32 \%$ respectively. In our study right sided nasal lesions including septum $(48.15 \%)$ were more common than left sided lesions (37.04\%). Bilateral presentation was seen in $8(14.81 \%)$ cases. In cases of sinonasal neoplasms which were arising from maxillary antrum, right sided lesions were (72.73\%) were more common than left $(27.27 \%)$.

In our study most of the benign and malignant lesions were arising from nasal cavity, whereas most of the indeterminant lesions were arising from maxillary antrum. Though individually most of the malignant lesions were arising from nasal cavity, but in respect to benign lesions malignant lesions were more in maxillary sinus.

In our study commonest clinical presentation was epistaxis (31.71\%), followed by nasal obstruction $(24.39 \%)$. Other symptoms like headache, pain, proptosis, purulent nasal discharge etc. were present in $14.36 \%$ cases (Table -2$)$.

In the present study it was seen that papilloma (34.09\%) is the most prevalent benign lesions followed by angiofibroma (27.27\%) (Fig V). Squamous cell carcinoma (27.27\%) is the most common malignancy followed by nasopharyngeal carcinoma (Fig VI), adenoid cystic carcinoma (12.12\%) each and small round cell tumour (CA) occupies third position (9.09\%) (Table $-3 \& 4)$.

In our study most of the benign lesions $(63.64 \%)$ were of mesenchymal origin followed by epithelial origin $(34.09 \%)$. In contrast to benign lesions, malignant neoplasms were mostly of epithelial origin $(69.70 \%)$ followed by mesenchymal $(21.21 \%)$ origin. But benign and malignant lesions when combined were mostly mesenchymal (48.78\%) followed by epithelial (46.34\%) and in a small percentage of cases , were neuroectodermal (4.88\%) (Fig. III).

In case of papilloma nasal obstruction (58.84\%) more than epistaxis (20\%). Whereas in case of hemangioma and angiofibroma epistaxis $(30 \%)$ and $(45 \%)$ respectively more common than nasal obstruction (7.69\%) in both type of the cases. In case of squamous cell carcinoma nasal obstruction, epistaxis though were commonest presentation.

\section{Discussion}

In our study it was seen that, males were more commonly affected (69.51\%) than females (30.49\%). In a similar type of study, which was carried out by Chan SH et $\mathrm{al}^{4}$,also showed that males ( $68.29 \%$ ) were outnumbered the females $(31.71 \%)$. This finding was similar as reported in the study conducted by Gras Cabrerizo JR et al ${ }^{5} 2006$ in which males were $75 \%$ females were $25 \%$. On the contrary M. Panduranga 
Kamath, Mahesh Chandra et al ${ }^{5}$ found that females were predominant possibly due to non neoplastic lesions like polyp were also included in their study.

The study conducted by Zyłka S, Bień S, Kamiński B, Postuła S, Ziołkowska M. ${ }^{6}$ et al on cases, age range from 8 to 82 years. They found maximum patient (59.8\%), both males and females, in the age above 60 years, among which most common age group 71-80 years(33.3\%). Where as minimum concentration was seen in our study over 71-80 years, might be due to lack of awareness, poor socioeconomic conditions .

The study conducted by U . Zafar,N Khan,N.Afroz,S.A.Hasan et al $2008^{7}$ reported a mean age of presentation of 22.5 years, in their study the age of presentation ranged from $1^{\text {st }}$ decade to $6^{\text {th }}$ decade, in their study youngest patient was 9 years old and the oldest patient was 58 years and the peak incidence was seen in the $2^{\text {nd }}$ and $3^{\text {rd }}$ decade of life. This might be due to the fact that they included only non-neoplastic lesions in their study while in our study we took neoplastic lesions only.

In our study it we found that anatomically most of the sinonasal lesion was located in the nasal cavity (57.32\%) followed by maxillary antrum (13.41\%). Dubey SP et al ${ }^{8} 1999$ reported 50 malignant tumors of the nasal cavity and paranasal sinuses that were managed in Papua New Guinea from 1986 to 1995. Twenty-nine of these arose in the maxillary sinus, 15 in the nasal cavity, four in the ethmoid sinus and two in the frontal sinus. The study conducted by Zyłka S, Bień S, Kamiński B, Postuła S, Ziołkowska M. et al on 87 cases $^{6}$,most common defined 22ocalization was maxillary sinus(33.3\%). But in $37.9 \%$ of cases, due to very advanced stage at time of diagnosis the precise localization within the region was not possible to define.

In the study conducted by Bielamowicz $\mathrm{S}$ et $\mathrm{al}^{9} 1993$ on 61 patients, reported that the most common symptom at presentation was nasal obstruction (71\%), followed by epistaxis (27\%). Plinkert PK 1997 also reported that the most common presenting symptoms was unilateral nasal obstruction. ${ }^{10}$ These findings are not similar to our findings where the most common presentation was epistaxis (31.71\%), followed by nasal obstruction $(24.39 \%)$. We grouped the lesions as benign, indeterminant and malignant according to nature of the lesion.The lesions which have high recurrence rate and require regular followup but fall short of criteria to categorise them as malignant or benign lesions have been called indeterminant in our study.

In contrast to our study, Anjali Dasgupta et al 1997 reported the most common benign lesion to be haemangioma (45.7\%) followed by angiofibroma (23.2\%), inverted papilloma accounted for only $3.9 \%$ of their cases. ${ }^{11}$ While among the malignant lesions squamous cell carcinoma (33.2\%) was found to be the most common lesion followed by $19.5 \%$ of adenoid cystic carcinoma like our study. Dubey Spet al 1999 also reported squamous cell carcinoma as the commonest type of tumour in their study.

Gras Cabrerizo JR et al 2006 performed a retrospective study of 72 carcinomas of the nasal cavity and paranasal sinuses where squamous cell carcinoma was the most frequent histological type in both localizations ${ }^{12}$ In our study where histopathological examination was taken as an ultimate diagnostic tool. We confirmed presumptive diagnosis done by endoscopy and imaging. So,according to our study report diagnostic sensitivity and specificity of imaging and endoscopy was $81.81 \%$ and $75 \%$ respectively. Positive predictive value $71.05 \%$ and negative predictive value $84.62 \%$.Similar study which was done by Ehab Hanna et $\mathrm{al}^{13}$,showed The sensitivity and specificity of CT in detecting PNS were $88 \%$ and $89 \%$, respectively. Magnetic resonance imaging had a higher sensitivity (100\%) and specificity (85\%).

\section{Tables}

TABLE - 1

Age and Sex distribution

\begin{tabular}{|l||l||l|}
\hline \multirow{2}{*}{ Age in years } & Sex distribution of study population \\
\cline { 2 - 3 } & Male & Female \\
\hline \hline$<10$ Yrs. & $3(3.66 \%)$ & $2(2.44 \%)$ \\
\hline \hline $10-20$ Yrs. & $9(10.97 \%)$ & $7(8.54 \%)$ \\
\hline \hline $21-30$ Yrs. & $8(9.76 \%)$ & $4(4.88 \%)$ \\
\hline \hline $31-40$ Yrs. & $7(8.54 \%)$ & $4(4.88 \%)$ \\
\hline \hline 41-50 Yrs. & $13(15.85 \%)$ & $5(6.09 \%)$ \\
\hline \hline $51-60$ Yrs. & $3(3.66 \%)$ & $1(1.22 \%)$ \\
\hline \hline 61-70Yrs & $11(13.41 \%)$ & $2(2.44 \%)$ \\
\hline \hline 71-80Yrs OF & $3(3.66 \%)$ & 0 \\
\hline \hline $\begin{array}{l}\text { TOTAL NO OT(69.51\%) } \\
\text { CASES }\end{array}$ & $25(30.49 \%)$ \\
\hline
\end{tabular}


TABLE - 2

Distribution of sinonasal masses according to the clinical presentation

\begin{tabular}{||l||l||}
\hline Clinical presentation & No of cases $(\%)$ \\
\hline \hline Nasal obstruction & $20(24.39 \%)$ \\
\hline \hline Epistaxis & $26(31.71 \%)$ \\
\hline \hline Both & $11(13.42 \%)$ \\
\hline \hline Mass in the sinonasal area & $13(15.85 \%)$ \\
\hline \hline Others & $12(14.63 \%)$ \\
\hline \hline Total & $\mathbf{8 2}(100 \%)$ \\
\hline
\end{tabular}

TABLE - 3

Distribution of benign sinonasal lesions

\begin{tabular}{|l||l||}
\hline Benign lesions & No of cases $(\%)$ \\
\hline \hline Papilloma & $15(34.09 \%)$ \\
\hline \hline Haemangiomas & $8(18.18 \%)$ \\
\hline \hline Angiofibroma & $12(27.27 \%)$ \\
\hline \hline Schwannoma & $3(6.82 \%)$ \\
\hline \hline Cementifying fibroma & $\mathbf{2}(4.54 \%)$ \\
\hline \hline Fibrous dysplasia & $1(2.27 \%)$ \\
\hline \hline Ameloblastoma & $1(2.27 \%)$ \\
\hline Craniopharyngioma & $1(2.27 \%)$ \\
\hline \hline Meningioma & $1(2.27 \%)$ \\
\hline \hline TOTAL & $44(100 \%)$ \\
\hline
\end{tabular}

TABLE - 4

Distribution of malignant sinonasal lesions

\begin{tabular}{||l||l||}
\hline Malignant lesions & No of cases $(\%)$ \\
\hline Squamous cell CA & $9(27.27 \%)$ \\
\hline Nasopharyngeal CA & $4(12.12 \%)$ \\
\hline Adenoid cystic CA & $4(12.12 \%)$ \\
\hline Small round cell tumor (CA) & $3(9.09 \%)$ \\
\hline \hline Lymphoma(NK/TCELL TYPE) & $1(3.03 \%)$ \\
\hline PLGA & $1(3.03 \%)$ \\
\hline \hline Papillary adenocarcinoma & $1(3.03 \%)$ \\
\hline Olfactory neuroblastoma & $2(6.06 \%)$ \\
\hline Alveolar rhabdomyosarcoma & $2(6.06 \%)$ \\
\hline Embryonal rhabdomyosarcoma & $1(3.03 \%)$ \\
\hline \hline Basal cell CA(BCC) & $2(6.06 \%)$ \\
\hline \hline Carcinoid tumour & $1(3.03 \%)$ \\
\hline \hline Sebaceous cell carcinoma & $1(3.03 \%)$ \\
\hline Poorly differentiated carcinoma & $1(3.03 \%)$ \\
\hline \hline Total & $33(100 \%)$ \\
\hline \hline
\end{tabular}




\section{FIGURES}

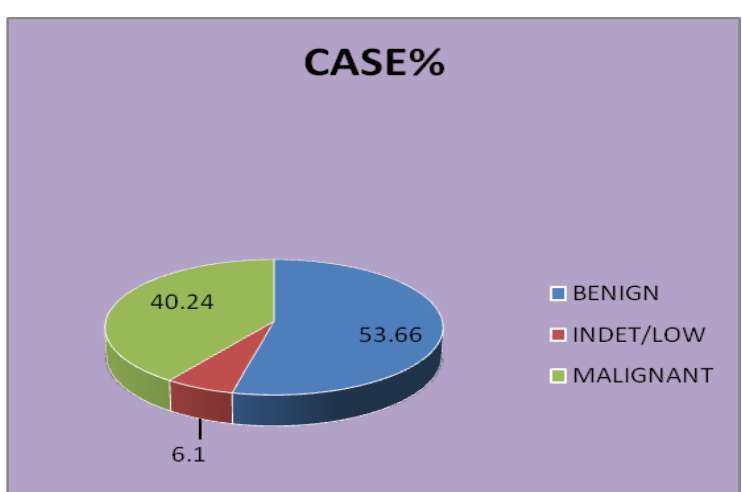

Figure I : Distribution or sinonasal neoprasm accoraing to the nature of the lesion

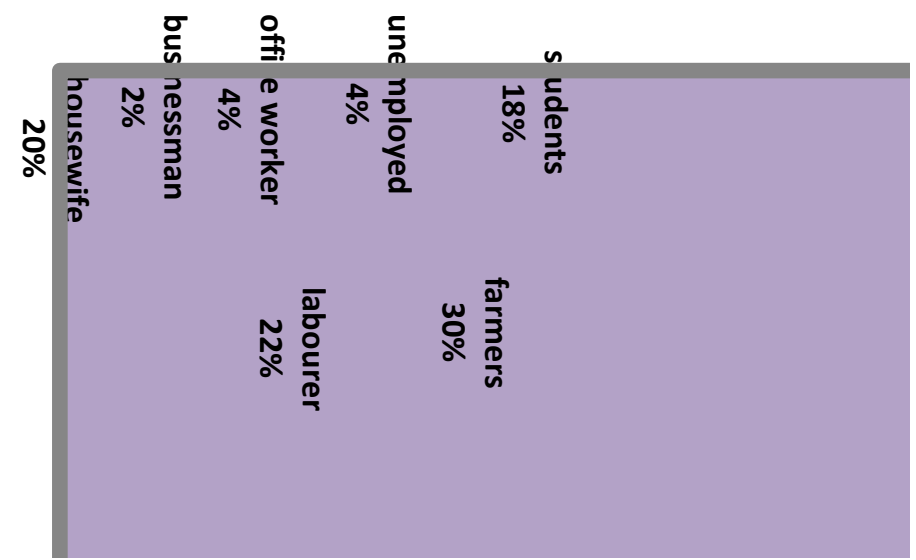

Figure II : Distribution of patients according to occupation

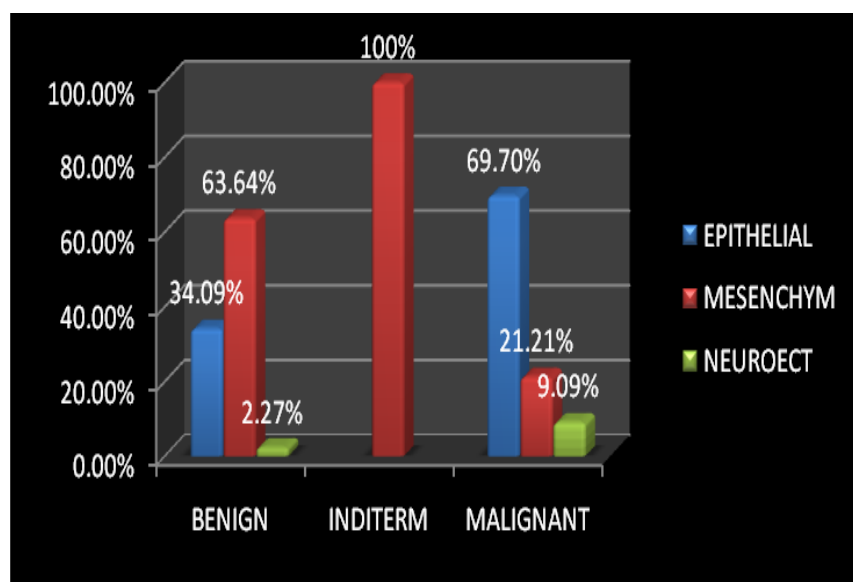

Figure III : Distribution of Benign,indeterminant and malignant sinonasal neoplasm according to their tissue of origin 


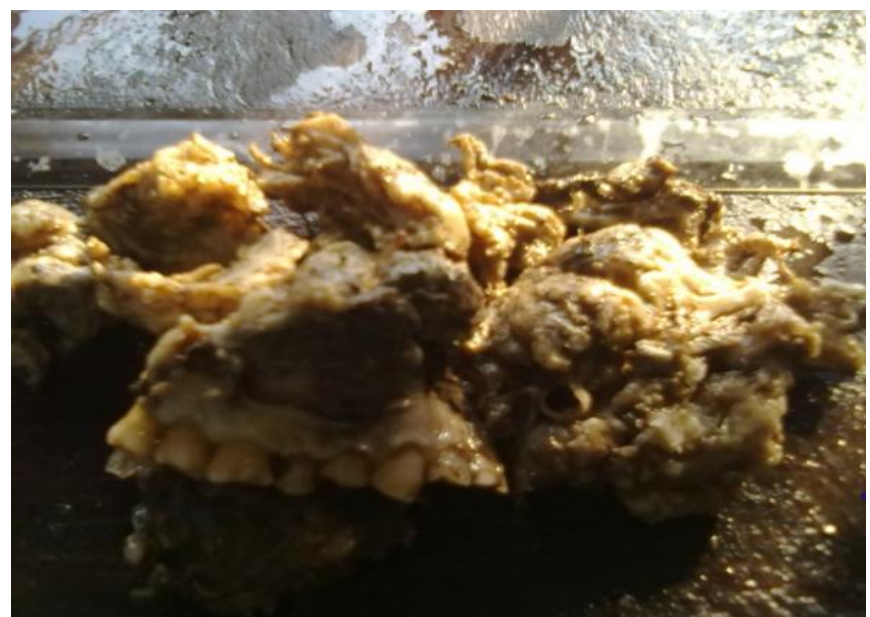

Figure IV : Gross photograph of maxilla containing a sinonasal mass

Haematoxilin \& Eosin, X 100

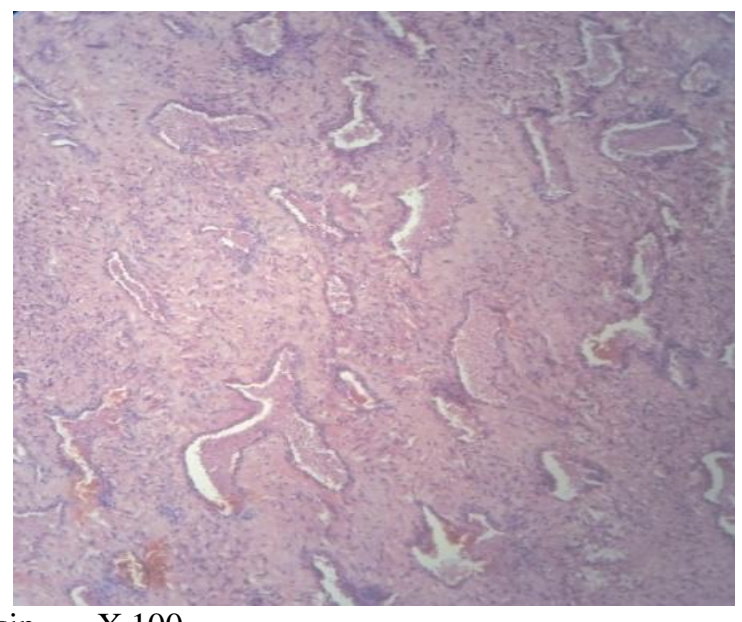

Figure V : Microphotograph showing histology of tumour mass composed of various size mostly thin walled,slit like(staghorn) vessels lined by plump endothelial cells without presence of muscular lining embedded within a fibrocollagenous stroma of nasopharyngeal angiofibroma

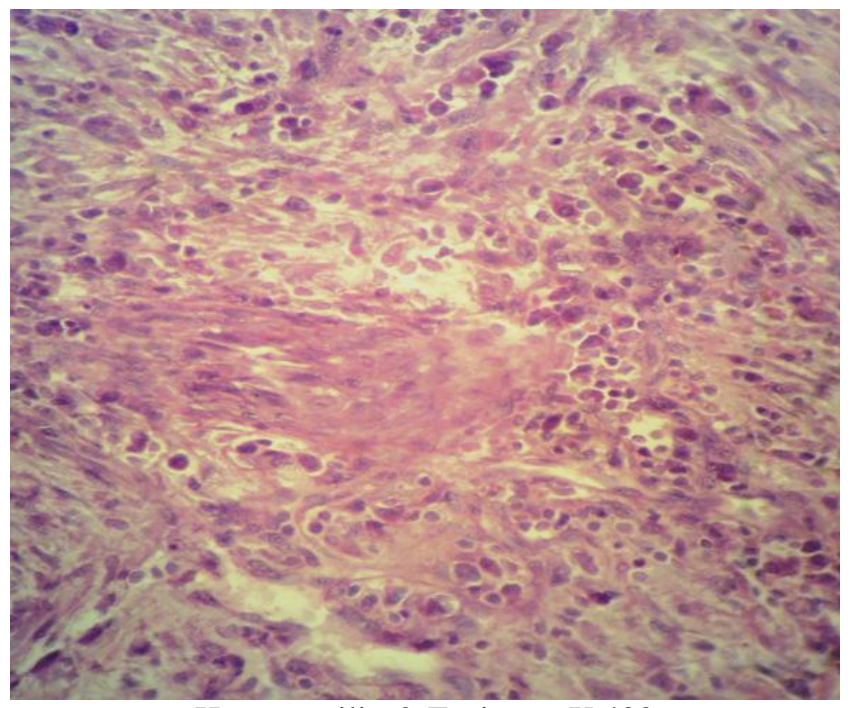

Haematoxilin \& Eosin, X 400

Figure VI : Photomicrography showing sheets of tumour cells having moderate amount of eosinophilic cytoplasm, large vesiclular nuclei and prominent eosinophilic nucleoli with occasional tumour mitosis and lymphocytic infiltrate suggestive of non-keratinising undifferentiated nasopharyngeal carcinoma. 


\section{Conclusion}

Sinonasal neoplasms have wide range of possibilities. Commonly, patients present with nasal obstruction and epistaxis. Early diagnosis with the help of newer diagnostic modalities with prompt treatment is necessary for these patients. Histopathological diagnosis is necessary for any neoplastic lesion in nasal cavity. This will guide us for further management of these lesions.

\section{References}

[1] Franchi A, Moroni M, Massi D, Paglierani M, Santucci M. Sinonasal.Undifferentiated carcinoma, nasopharyngeal-type undifferentiated carcinoma, and keratinizing and nonkeratinizing squamous cell carcinoma express different cytokeratin pattern. AmJ Surg Pathol 2002; 26:1597-604.

[2] BarnesL,Everson J,Reichart P,Sidransky D,eds World Health Organization Classification of tumours.Pathology and Genetics.Head and Neck Tumours.Lyon:IARC Press;2005.

[3] www.medcal.org

[4] Chan SH, Day NE, Kunaratnam N, Chia KB, Simons MJ. HLA and nasopharygeal carcinoma in Chinese. A further study. Int. J. Cancer 1983, 32: 171-176.

[5] M. Panduranga Kamath1, Mahesh Chandra et al.Antrochoanal polyps and allergy- a comparative study. Indian Journal of Otolaryngology and Head and Neck Surgery 2002;54.

[6] Zyłka S, Bień S, Kamiński B, Postuła S, Ziołkowska M Epidemiology and clinical characteristics of the sinonasal malignancies Otolaryngol Pol. 2008;62(4):436-41.

[7] U. Zafar,N Khan, N.Afroz, S.A.Hasan. Clinicopathological study of non-neoplastic lesions of nasal cavity and para nasal sinuses.Indian journal of pathology and microbiology 2008;51:26-29.

[8] Dubey SP, Murthy DP, Kaleh LK, Vele DD. Malignant tumours of the nasal cavity and the paranasal sinuses in a Melanesian population. Auris Nasus Larynx 1999;26:57-64.

[9] Bielamowicz S, Calcaterra TC, Watson D. Inverting papilloma of the head and neck: the UCLA update. Otolaryngol Head Neck Surg 1993;109:71-6.

[10] Plinkert PK, Ruck P, Baumann I, Scheffler B. Inverted papilloma of the nose and paranasal sinuses--diagnosis, surgical procedure and studies of cytokeratin profile. Laryngorhinootologie 1997;76:216-24.

[11] Dasgupta A, Ghosh RN, Mukherjee C. Nasal polyps-Histhopathological spectrum. .Indian journal of Otolaryngology and Head and Neck Surgery 1997;49:32-6.

[12] Gras Cabrerizo JR, Orús Dotú C, Montserrat Gili JR, Fabra Llopis JM, León Vintro X, De Juan Beltrán J. Epidemiologic analysis of 72 carcinomas of the nasal cavity and paranasal sinuses. Acta Otorrinolaringol Esp 2006;57:359-63.

[13] Ehab Hanna, MD; Emre Vural, MD; Emmanuel Prokopakis, MD; Ricardo Carrau, MD; Carl Snyderman, MD; Jane Weissman, MD : The Sensitivity and Specificity of High-Resolution Imaging in Evaluating Perineural Spread of Adenoid Cystic Carcinoma to the Skull Base, Arch Otolaryngol Head Neck Surg. 2007;133(6):541-545. 